\title{
Parameter analysis of non-metallic inclusion formation in thermite alloys
}

\author{
Ihor Skidin ${ }^{1}$, Oksana Vodennikova $^{2}$, Sergii Vodennikov $^{3}$, Levan Saithareiev ${ }^{1}$, and Shamil Telkov ${ }^{4}$ \\ ${ }^{1}$ Kryvyi Rih National University, Metallurgy \& Foundry Department of Ferrous Metals, Ukraine \\ ${ }^{2}$ Zaporizhzhia National University, Department of Metallurgy, Ukraine \\ ${ }^{3}$ Zaporizhzhia Polytechnic National University, Department of Machines and Foundry Technology, Ukraine \\ ${ }^{4}$ Satbayev University, Metallurgy and Mineral Processing Department, Kazahstan
}

\begin{abstract}
The methodology of calculating parameters of the primary and secondary non-metallic inclusion formation in thermite alloys is offered. The regularities of the growth time of non-metallic inclusion in the form of corundum depending on its size, mass and quantity are analysed. It is shown that in the thermite alloy obtained by self-propagating high-temperature synthesis, the average size of corundum inclusions, surrounding the heterogeneous inclusions of chromium carbide, is $15.4 \mu \mathrm{m}$. It is shown that during the process of aluminothermic reactions of the SHS process a significant number of small inclusions of corundum is formed. It is shown that the alumina particles are dissolved in the alloy and they are the centers of crystallization and play the role of inoculating modifier.
\end{abstract}

\section{Introduction}

Today, one of the main indicators of metal quality and, correspondingly, the quality of final products is the contamination of non-metallic inclusions, and both the number of inclusions and their nature and physicochemical composition matter [1]. It should be noted that special attention is paid to the role of fine nonmetallic inclusions in the process of the microstructure forming of steel in liquid and solid states. It is shown that the influence of fine non-metallic inclusions on the formation of the primary and secondary microstructure of steel is due to their interaction in the liquid metal melt with clusters, as well as the action of both crystallization nuclei and inhibitors of growth of the primary crystals [2]. Non-metallic inclusions significantly reduce the technological and mechanical properties of steels, contributing to the formation of various defects. One of the ways to solve the important task to increase the strength and plasticity of steels is to reduce contamination by non-metallic inclusions, reduce their size, and ensure their even distribution. During the different influences, the diverse kinds of phase and structural rearrangements occur in non-metallic inclusions, which contributes to the size changes of inclusions, their phase and structural state modifications and undoubtedly affects the local areas of the steel matrix near non-metallic inclusions. The nature of these modifications can significantly change the adhesion bonds at the inclusion-matrix interfacial boundaries [3]. The problem of controlling non-metallic inclusions is based primarily on the estimation not only of the inclusion's total number, but also the inclusion's critical size, and the assessment of the compositions; the size-based distribution of inclusions [4].

One of the unsolved problems of the metallurgical processes theory is the reliable calculation of the mass, size, and composition of non-metallic inclusions in steel. There is a large array of experimental data on this topic, but the available theoretical developments can only claim to solve certain aspects of the problem for a few classes of non-metallic inclusions [5]. Thus, in [6,7] there is a systems review of non-metallic inclusions $\mathrm{FeO}-\mathrm{MnO}-$ $\mathrm{SiO}_{2}-\mathrm{Al}_{2} \mathrm{O}_{3}$, which are most common in the practice of steelmaking.

In [3] the processes of steel destruction near nonmetallic inclusions are analyzed and the peculiarities of the structure of inclusions as phases of introduction and their influence on the occurrence of the thermal and deformation stresses are discussed. The author shows the influence of the non-metallic inclusions nature on the mechanism of microdestruction formation in steel under the different deformation conditions; and also - inactive areas.

Based on Gibbs' method of chemical potentials, the thermodynamic relations, describing the origin and growth of non-metallic inclusions in steel, were obtained [8]. The influence of non-metallic inclusions on the properties and structure of the different types of steel is described in [9-16]. The influence of the morphology of non-metallic inclusions on the destruction of highstrength corrosion-resistant steel was carried out in [17]. The conditions for reducing the content of non-metallic 
inclusions, such as oxide and sulfide in corrosion-resistant nitrogen-containing steel, are considered in [18]. The authors in [19] proposed measures to reduce the size and number of non-metallic inclusions in the cord steel. They used the method of estimating non-metallic inclusions, which was developed by the author [20]. The share of the area occupied by non-metallic inclusions is one of the evaluation criteria.

The estimation of large single non-metallic inclusions in steel in accordance with the statistics of extreme values is given in [21].

The method for determining the mass of corundum inclusions in steel was proposed in [22]. In order to do this, the concentration of aluminum bound in oxides was found firstly:

$$
[A l]_{\text {oxigen }}=[A l]_{\text {general }} \cdot 0,675 .
$$

Then, using the known molar mass of the elements in the formula of alumina, and knowing the mass of the metal in the ladle, the mass was determined:

$$
m_{\mathrm{Al}_{2} \mathrm{O}_{3}}=\frac{[\mathrm{Al}]_{\text {oxigen }} \cdot 1,89 M_{\mathrm{Me}}}{100 \%} .
$$

Analysis of the impact of corundum inclusions on the mechanical and technological properties of steel shows the contradictory nature of research. Thus, the authors of [23] argue that the inclusion of corundum impairs the technological properties of steel, especially if they form clusters. And in [24] it was noted that corundum does not have a negative effect on technological plasticity, but on the contrary, even increases it, while cracks are usually formed in silicates.

On the example of simple carbides $\left(\mathrm{M}_{6} \mathrm{C}, \mathrm{M}_{23} \mathrm{C}_{6}, \mathrm{M}_{3} \mathrm{C}\right.$, $\mathrm{M}_{7} \mathrm{C}_{3}, \mathrm{M}_{2} \mathrm{C}$ and MS types) with the help of their crystalchemical and thermodynamic analysis the influence and probability of phase transitions, in both liquid and solid steel under the thermal and thermoplastic influence, were evaluated in the work [25]. The study of the specifics of the influence of alloying elements on the composition of carbides of the $\mathrm{MS}$ and $\mathrm{M} 23 \mathrm{C} 6$ types in the multicomponent $\mathrm{Ni}-13.5 \mathrm{Cr}-5 \mathrm{Co}-3.4 \mathrm{Al}-4.8 \mathrm{Ti}-$ $7.3 \mathrm{~W}-0.8 \mathrm{Mo}-0.015 \mathrm{~B}-0.12 \mathrm{C}$ system was carried out in work [26].

In the work [27] the attention was paid to the study of the structure and properties of a wear-resistant alloy, based on cobalt with niobium carbide. The work [28] is devoted to the study of the regularities of combustion of powder and granular mixtures of $\mathrm{Ti}-\mathrm{C}-\mathrm{Ni}$ with the different mass fraction of $\mathrm{Ni}$ in the mixture and the analysis of synthesis products by the different methods. It is shown that the average grain size of carbide is $2-4 \mu \mathrm{m}$, which is an order of magnitude smaller than the original size of titanium particles $(50 \mu \mathrm{m})$, i.e. during combustion is the so-called «self-dispersion» of titanium particles, and the nickel bond prevents the growth of titanium carbide synthesis.

The issue of predicting the release of carbidonitrides and carbides in microalloyed steel using thermodynamic calculations is disclosed in the work [29]. The calculation of the chemical composition and total mass of non- metallic inclusions in the course of out-of-furnace processing and casting of steel is given in the work [30]. The authors of the following work [30] found that the composition of inclusions in both deoxidized and nondeoxidized aluminum steel is well amenable to thermodynamic modeling taking into account the influence of slag and other factors, for example, the receipt of aluminum as an impurity in ferroalloys).

The above confirms the need to expand research in the field of studying the effect of non-metallic inclusions on the physicochemical properties and structure of steel.

The issue of calculating the parameters of formation of non-metallic inclusions is insufficiently studied, so it seems appropriate to propose a method of calculating the parameters of formation of non-metallic inclusions, as the primary as secondary in thermite alloys.

\section{Results and discussion}

It is known that in order to obtain a dense SHS-material with high physical and mechanical characteristics, it is necessary to take into account the patterns of combustion of the reaction mixture, the formation of chemical and phase compositions of the final product, the crystallization behavior of the alloy [31]. As it is noted in [32] during the formation of a thermite alloy layer of the $\mathrm{Fe}-\mathrm{Cr}-\mathrm{C}$ system on a metal-based SHS process, the layer formation zone is characterized by macrostructure stability and positive effect of oxidative nonmetallic inclusion in the form of corundum (as $\alpha$-modifications of $\mathrm{Al}_{2} \mathrm{O}_{3}$ ). Corundum, creating the effect of inoculating modification of the thermite alloy, in turn, promotes the formation of chromium carbides in the resulting thermite alloy.

The total reaction, which determines the overall material balance of the process of forming a layer of thermite alloy in the SHS process, has the form [33]:

$$
\begin{aligned}
& 6\left(\mathrm{Fe}_{2} \mathrm{O}_{3}\right)_{\mathrm{sl}}+6(\mathrm{Al})_{\mathrm{sl}}+13(\mathrm{C})_{\mathrm{sl}}+(\mathrm{Fe})_{\mathrm{sl}} \rightarrow 9(\mathrm{CO}) \uparrow+(\mathrm{C}) \uparrow+ \\
& +(\mathrm{Fe}) \uparrow+\mathrm{Fe}_{\mathrm{Me}}+3\left(\mathrm{Fe}_{3} \mathrm{C}\right)_{\mathrm{Me}}+\left(\mathrm{Al}_{2} \mathrm{O}_{3}\right)_{\mathrm{Me}}+2\left(\mathrm{Al}_{2} \mathrm{O}_{3}\right)_{\mathrm{sl}} .(3)
\end{aligned}
$$

The reaction of formation of chromium carbides has the following form:

$$
2(\mathrm{Cr})_{\mathrm{Me}}+(\mathrm{C})_{\mathrm{Me}} \rightarrow\left(\mathrm{Cr}_{2} \mathrm{C}\right)_{\mathrm{Me}}
$$

In the formed layer of thermite alloy complex carbide phase contains $78.7 \%$ of the mass. $\mathrm{Fe}+14.6 \%$ of the mass. $\mathrm{Cr}+6.7 \%$ wt. $\mathrm{C}$ and/ is formed according to the reaction:

$$
\mathrm{Fe}_{\mathrm{Me}}+3\left(\mathrm{Fe}_{3} \mathrm{C}\right)_{\mathrm{Me}}+\left(\mathrm{Cr}_{2} \mathrm{C}\right)_{\mathrm{Me}} \rightarrow \mathrm{Fe}_{10} \mathrm{Cr}_{2} \mathrm{C}_{2} \rightarrow 2\left(\mathrm{Fe}_{5} \mathrm{CrC}\right) .
$$

The distribution of chemical elements of charge materials in the formation of a layer of thermite alloy based on iron, the SHS process is determined according to the method [33] from the material balance of the reaction (3):

$$
\begin{aligned}
\Sigma(3+4): 6\left(\mathrm{Fe}_{2} \mathrm{O}_{3}\right)_{\mathrm{sl}} & +6(\mathrm{Al})_{\mathrm{sl}}+2(\mathrm{Cr})_{\mathrm{sl}}+14(\mathrm{C})_{\mathrm{sl}} \rightarrow 9(\mathrm{CO}) \uparrow+ \\
+(\mathrm{C}) \uparrow+(\mathrm{Cr}) \uparrow & +(\mathrm{Fe}) \uparrow+\mathrm{Fe}_{\mathrm{Me}}+3\left(\mathrm{Fe}_{3} \mathrm{C}\right)_{\mathrm{Me}_{\mathrm{e}}}+\left(\mathrm{Cr}_{2} \mathrm{C}\right)_{\mathrm{Me}}+ \\
& +\left(\mathrm{Al}_{2} \mathrm{O}_{3}\right)_{\mathrm{Me}}+2\left(\mathrm{Al}_{2} \mathrm{O}_{3}\right)_{\mathrm{sl}} .
\end{aligned}
$$

Due to the fact that the liquid phase of the thermite 
melt is stored on the metal surface of the casting for a short time (15-25 seconds), mixed in the formed functional layer corundum does not have time to affect the slag in full and affects the formation of metal structure.

According to [34], the formation of a new phase inside the melt begins with embryos. Embryos, as a new phase, can be formed when the melt is supersaturated with the components of the new phase.

If we imagine that the nuclei of the new phase are formed on the seed, we should take into account their higher solubility and higher melting point compared to the formed metal phase solid + liquid with larger crystals. Therefore, for further growth, the embryos of the new phase must exceed some critical size.

During aluminothermic reactions of the SHS process, a melt consisting of iron and aluminum oxides is formed firstly. If in the first approximation we accept the inclusion of critical size in the form of a spherical embryo, then to calculate the formation of the embryo from the melt, we can use the formula [34]:

$$
r_{k}=\frac{2 \sigma_{S L} \cdot M_{r}}{\rho R T \ln C_{r} / C},
$$

where $r_{k}$ - critical radius of the embryo, cm; $\sigma_{\mathrm{SL}}-$ interfacial tension, $\mathrm{erg} / \mathrm{cm}^{2} ; \quad C_{r} / C=\alpha \quad-$ melt supersaturation; $M_{r}$ - molecular weight of non-metallic inclusion, $\mathrm{g} / \mathrm{mol} ; \rho$-density of the chemical compound, $\mathrm{kg} / \mathrm{m}^{3} ; R$ - gas constant, which is equal to $8,3143 \cdot 10^{7}$ $\mathrm{erg} / \mathrm{mol} ; T$ - melting point of the compound, $\mathrm{K}$.

The supersaturation of the melt for alumina is equal to:

$$
\alpha_{A l_{2} O_{3}}=\frac{K_{f}}{K_{A l}}=\frac{[\% A l]_{f}^{n} \cdot[\% O]_{f}^{m}}{K_{A l}},
$$

where $K_{A l}$ - equilibrium constant of aluminum; $f$ - index indicating the actual concentrations of aluminum and oxygen dissolved in liquid iron.

According to the formula of alumina $\mathrm{Al}_{2} \mathrm{O}_{3}$, the values $n=2$ and $m=3$ are taken.

The maximum solubility of oxygen in liquid iron is $0.17 \%$.

Determine the equilibrium constant for aluminum at a temperature of $1873 \mathrm{~K}$ according to the formula:

$$
\lg K_{A l}=\frac{-64000}{1873}+20,48
$$

Accordingly:

$$
\begin{gathered}
K_{A l}=2,046 \cdot 10^{-14} . \\
\alpha_{A l_{2} \mathrm{O}_{3}}=\frac{[30]_{f}^{2} \cdot[0,17]_{f}^{3}}{2,046 \cdot 10^{-14}}=1,71 \cdot 10^{16} .
\end{gathered}
$$

Let's accept for oxidative non-metallic inclusion in the form of $\mathrm{Al}_{2} \mathrm{O}_{3}$ :

$$
\sigma_{S L A l_{2} O_{3}}=23373 \mathrm{erg} / \mathrm{cm}, \ln \alpha_{\mathrm{Al}_{2} \mathrm{O}_{3}}=37,377 .
$$

Substituting the obtained data, the critical radius of the embryo $\mathrm{Al}_{2} \mathrm{O}_{3}$ is equal to:

$$
r_{k_{A_{2} O_{3}}}=\frac{2 \cdot 2337 \cdot 102}{4 \cdot 8,3143 \cdot 10^{7} \cdot 1873 \cdot 37,77}=2,095 \cdot 10^{-8} \mathrm{~cm} .
$$

Substituting the obtained data, the critical radius of the embryo $\mathrm{Al}_{2} \mathrm{O}_{3}$ is equal to:

Calculate the critical radius of chromium carbide inclusions $\left(\mathrm{Cr}_{3} \mathrm{C}_{2}\right)$, taking the chromium content of $28 \%$ and the carbon content of iron in $4 \%$.

Determine the equilibrium constant for chromium at a temperature of $1873 \mathrm{~K}$ according to the formula:

$$
\lg K_{C r}=\frac{-20260}{1873}+7,357 .
$$

Therefore $K_{c}=0.0316$

The supersaturation of the melt for chromium carbide is equal to:

$$
\alpha_{C_{3} C_{2}}=\frac{K_{\phi}}{K_{C r}}=\frac{[\% C r]_{f}^{n} \cdot[\% C]_{f}^{m}}{K_{C r}},
$$

According to the formula of chromium carbide $\mathrm{Cr}_{3} \mathrm{C}_{2}$ values are $n=3$ and $m=2$.

Then we get:

$$
\alpha_{\mathrm{Cr}_{3} \mathrm{C}_{2}}=\frac{[28]_{f}^{3} \cdot[4]_{f}^{2}}{0,0316}=11114937, \ln \alpha_{\mathrm{Cr}_{3} \mathrm{C}_{2}}=16,22 .
$$

To determine the interfacial tension of non-metallic inclusions should take into account their melting point. According to [34], we assume the melting temperatures of $\mathrm{Al}_{2} \mathrm{O}_{3}$ and $\mathrm{Cr}_{3} \mathrm{C}_{2}$ are equal to $2044{ }^{\circ} \mathrm{C}$ and $1895{ }^{\circ} \mathrm{C}$, respectively. Calculate the interfacial tension for chromium carbide:

$$
\begin{gathered}
\sigma_{S L C_{3} C_{2}}=3,328 T_{m}-4416 \\
\sigma_{S L C r_{3} C_{2}}=3,328 \cdot 1895-4416=1890 \mathrm{epz} / \mathrm{cm}^{2} .
\end{gathered}
$$

Substituting the obtained data, the critical radius of the embryo $\mathrm{Cr}_{3} \mathrm{C}_{2}$ is equal to:

$$
r_{k_{C_{3} C_{2}}}=\frac{2 \cdot 1890 \cdot 180}{6,68 \cdot 8,3143 \cdot 10^{7} \cdot 1873 \cdot 16,22}=24,032 \cdot 10^{-8} \mathrm{~cm} .
$$

The critical size of the non-metallic inclusion of $\mathrm{Al}_{2} \mathrm{O}_{3}$ is $3.85 \cdot 10^{-23} \mathrm{~cm}^{3}$, and $\mathrm{Cr}_{3} \mathrm{C}_{2}-2,746 \cdot 10^{-22} \mathrm{~cm}^{3}$.

It should be noted that the probability of formation of the critical size of the embryo of non-metallic inclusion increases with decreasing its size and increasing the supersaturation of the melt [35]. Therefore, the probability of homogeneous nucleation of alumina inclusions is much higher than the inclusions of chromium carbide.

Chromium carbide inclusions are formed heterogeneously on oxidative inclusions of $\mathrm{Al}_{2} \mathrm{O}_{3}$ as on seeds. This statement is reflected in the macrostructure of the iron-based thermite alloy sample, where a significant number of carbide inclusions surround small crystalline inclusions, which were identified by the metallographic analysis as corundum inclusions (Fig. 1).

The metallographic analysis shows that the average 
size of corundum inclusions surrounding the heterogeneous chromium carbide inclusions is $15.4 \mu \mathrm{m}$ $\left(1.54 \cdot 10^{-3} \mathrm{~cm}\right)$.

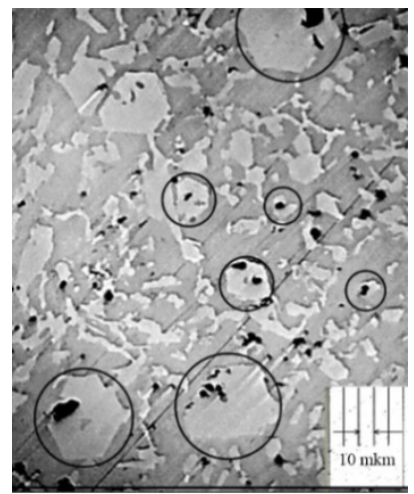

Fig. 1. Inclusion of corundum in the macrostructure of ironbased thermite alloy.

The nature of nonmetallic inclusions concentrated in a thermite alloy obtained by the SHS process on pure iron powder as a metal filler was investigated on undigested metallographic sections on an MIT-8 optical horizontal microscope (light field mode). Used iron powder by PZHRV brand 2.300.28 (GOST 9849-86) fraction $<300$ $\mu \mathrm{m}$.

Analysis of the macrostructure of sample №1 showed that nonmetallic inclusions, probably of exogenous origin, are rare in the metal base (Fig. 2, a). Mostly disoriented oxides up to $5 \mu \mathrm{m}$ in size were observed. The formed layer of thermite alloy presents globular and acute inclusions of $\mathrm{Al}_{2} \mathrm{O}_{3}$ (Fig. 2, b), which were identified as the primary inclusions that were not removed from the metal.

In sample №2 in the formed layer of the thermite alloy there are globular inclusions of pink color, which can be identified as iron oxides (Fig. 2, c). In the area close to the surface, there are elongated clusters of corundum inclusions, and exogenous slag inclusions of the products of the reaction of iron oxide with aluminum (Fig. 2, d). In sample №3 in the formed layer of thermite alloy there are accumulations of small inclusions of corundum (Fig. 2, e, f), inclusions of chromites (Fig. 2, g) (it should be assumed that chromium got into the thermite charge from rolled scale) and exogenous slag inclusions (Fig. 2, h).

To obtain a wear-resistant alloy was added to the thermite charge carburetor for carburization in the form of a modifier by MK91Abrand fraction up to $5 \mathrm{~mm}$ and chromium powder by PHA brand (GOST 14-00186482051-2005) fraction $300 \mu \mathrm{m}$. Analyzing the macrostructure of the formed thermite alloy layer, it was determined that the carbide component predominates in the samples (Fig. 3).

In the process of alumothermic reactions of the SHS process, a significant number of small inclusions of corundum are formed, which serve as centers of crystallization in the formation of carbide inclusions and play an important role in the nucleation of chromium carbides.

It should be noted that taking into account the presence of metallic chromium in the initial charge during the formation of a layer of thermite alloy based on iron, which significantly reduces the final melt temperature, we assume it equal to $2000{ }^{\circ} \mathrm{C}$, which is much lower than boiling temperature at atmospheric pressure of iron and aluminum.
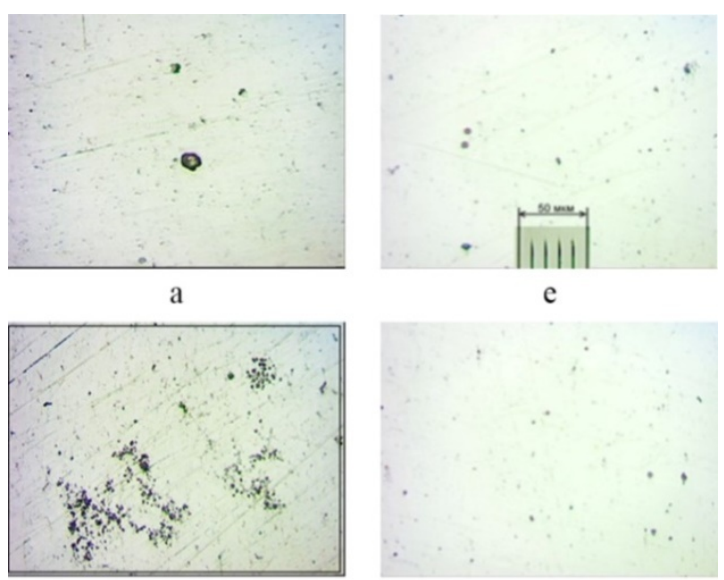

b

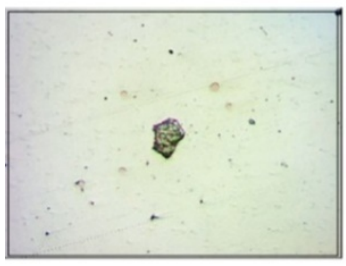

c

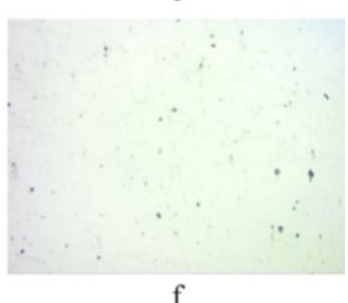

f

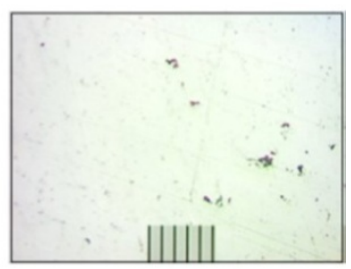

g
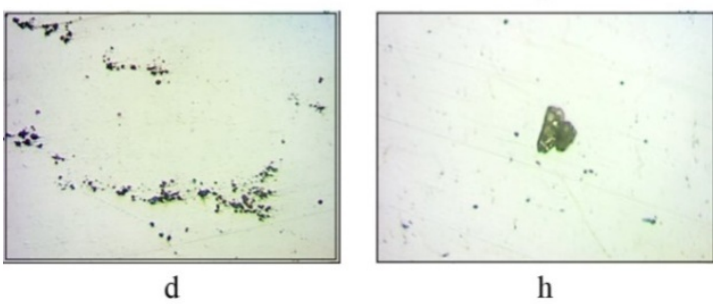

Fig. 2. Macrostructure of thermite alloy obtained by the SHS process on the pure iron powder of PZHRV brand 2.300.28.

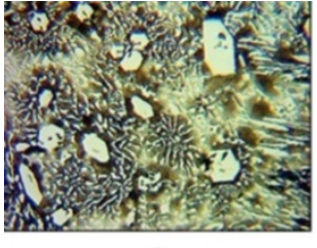

a

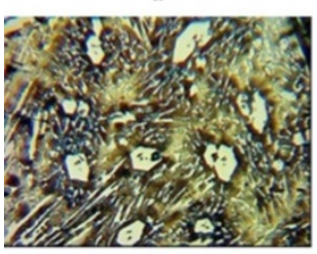

b

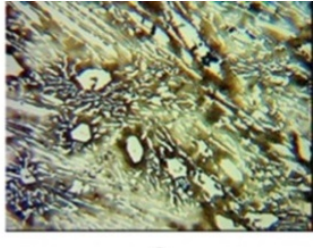

c

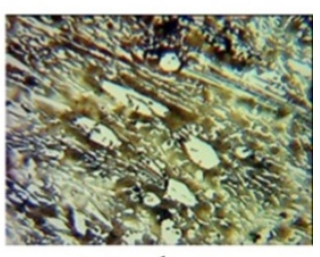

d
Fig. 3. Macrostructure of the thermite alloy obtained by the SHS process with the addition of PHA chromium powder: (a) -(d) samples №1-№4 (with etching).

It is known that most of the aluminum is consumed in the process of aluminothermic reaction of the SHS process. According to the diagram of the state of the iron - aluminum part (Fig. 4), about $5 \%$ of aluminum dissolves in liquid iron at a temperature of $1536{ }^{\circ} \mathrm{C}$. 


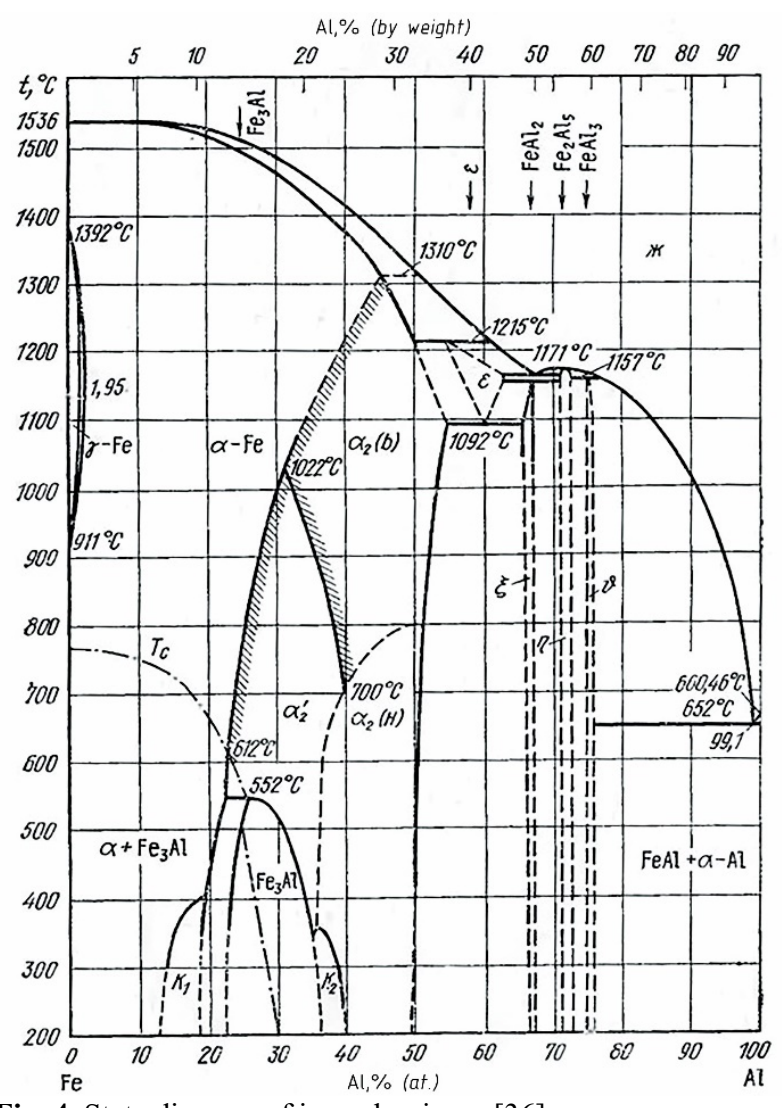

Fig. 4. State diagram of iron-aluminum [36].

Therefore, it seems appropriate to determine the supersaturation of the components that form non-metallic inclusions of corundum in the molten iron.

For the primary inclusions, the equilibrium constant according to the formula of Hoxen and Chipman [34] is:

$$
\lg K_{\mathrm{Al}}^{\mathrm{pi}}=\lg \left(a_{A l}^{2} a_{O}^{3}\right)=-\frac{64000}{T}+20,48 .
$$

At the temperature of $1973 \mathrm{~K}$ it is equal to:

$$
\lg K_{A l}^{p i}=-\frac{64000}{1973}+20,48=-11,96 .
$$

Therefore:

$$
K_{A l}^{p i}=10^{-12} .
$$

According to the dependence of the solubility of oxygen in iron on temperature (Fig. 5), we assume the solubility of oxygen equal to $0.339 \%$ at a temperature of $1973{ }^{\circ} \mathrm{C}$.

At a temperature of $1973{ }^{\circ} \mathrm{C}$ we take the solubility of oxygen equal to $0.339 \%$.

According to formula (8), the supersaturation of the melt is equal to:

$$
\alpha_{A l_{2} O_{3}}^{p i}=\frac{5^{2} \cdot 0,339^{3}}{10^{-12}}=9,74 e^{11} .
$$

According to formula (7), the critical radius of the embryo $\mathrm{Al}_{2} \mathrm{O}_{3}$ is equal to:

$$
r_{\mathrm{k}}^{\mathrm{pi}}{ }_{{ }_{12} \mathrm{O}_{3}}=\frac{2 \cdot 2337 \cdot 102}{4 \cdot 8,3143 \cdot 10^{7} \cdot 1973 \cdot \ln 9,74 e^{11}}=5,152 e^{-6} \mathrm{~cm} .
$$

When determining the number of the primary inclusions, we calculate for the mass of the formed layer of thermite alloy based on iron $100 \mathrm{~kg}$.

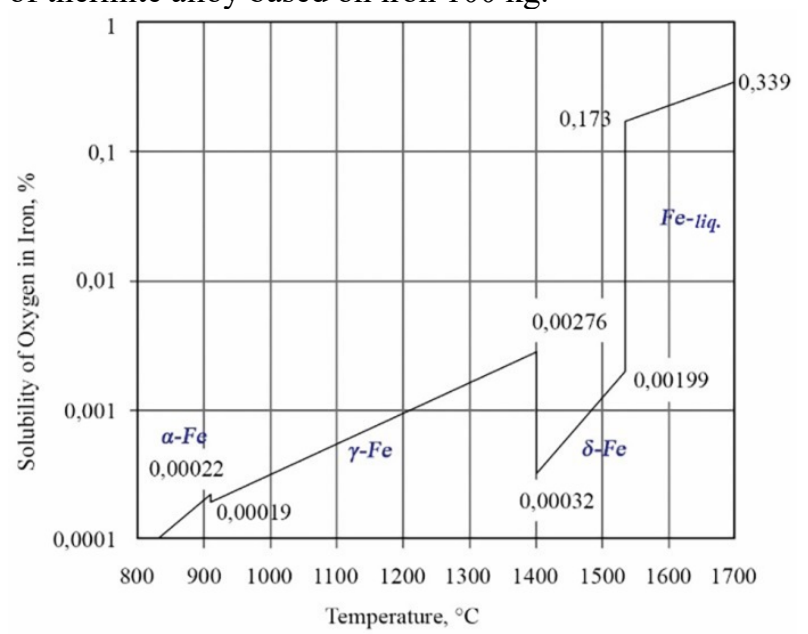

Fig. 5. Diagram of the solubility of oxygen in iron [37].

The density of the thermite alloy is $7.2 \mathrm{~g} / \mathrm{cm}^{3}$ and its volume is $13889 \mathrm{~cm}^{3}$. The density of corundum inclusions is $4 \mathrm{~g} / \mathrm{cm}^{3}$.

The volume of non-metallic inclusion of the critical size is equal to:

$$
\mathrm{V}_{\mathrm{k}}^{\mathrm{pi}}=4 / 3 \pi r^{3}, V_{k}^{p i}=4 / 3 \cdot 3,14 \cdot\left(5,152 e^{-6}\right)^{3}=5,73 e^{-16} \mathrm{~cm}^{3} .
$$

The mass of the non-metallic inclusion of the critical size is equal to:

$$
M_{k}^{p i}=V_{k}^{p i} \cdot \rho_{k}, M_{k}^{p i}=5,73 e^{-16} \cdot 4=2,29 e^{-15} g .
$$

Both aluminum and oxygen are used to form corundum inclusions, and the limiting element is oxygen that is dissolved in the melt.

$100000 \mathrm{~g}$ of melt contains $0.339 \cdot 100000 / 100=359 \mathrm{~g}$ of oxygen $\left(\mathrm{O}_{2}\right)$.

The mass of aluminum is: $359 \cdot 54 / 48=404 \mathrm{~g}$.

The total mass of corundum is: $404+359=763 \mathrm{~g}$.

Determine the number of inclusions of critical size:

$$
\frac{M_{A L_{0} O_{3}}}{M_{k}^{n}}=\frac{763}{2,29 e^{-15}}=3,33 e^{15} .
$$

According to the work of Bogdandi L. [38], the existence of a free symmetric circular diffusion field around the embryo is assumed. Based on Fick's second diffusion law [39], the following embryo growth equation was proposed:

$$
r=r_{0}+2 V D\left(C_{\infty}-C r\right) t,
$$

where $r$-inclusion radius to time $\mathrm{t}, \mathrm{cm} ; r_{0}$ - the radius of inclusion at time $t=0 \mathrm{~s}, \mathrm{~cm} ; V-$ molecular volume of oxide, $\mathrm{m}^{3} ; D$-diffusion coefficient of oxide components; $C_{\infty}$ - diffusion coefficient of oxide components in the melt; $C_{r}$ - concentration of oxides in the surface of the non-metallic inclusion.

For the primary inclusions, the growth of embryos is:

$$
r^{p i}=5,152 e^{-6}+2 \cdot 25,5 \cdot 1,5 \cdot 10^{-4}(0,339-0,173) t .
$$

It should be noted that in the process of growth of non- 
metallic inclusions must follow the law of conservation of mass [40]. If two germs of non-metallic inclusions are located next to each other, then the growth of one germ of critical size is necessarily accompanied by the dissolution of the other. Therefore, as the diffusion increases, the total number of non-metallic inclusions decreases.

The change in the size of the primary inclusions of corundum depending on time is presented in table 1 . It is determined that in $0.1 \mathrm{~s}$ the inclusions reach the dimensions sufficient for floating through the formed layer of thermite melt $10 \mathrm{~cm}$ thick for $6 \mathrm{~s}$. Virtually all the primary inclusions are concentrated on the surface of the melt and form layer consisting of small particles of corundum.

The number of the primary non-metallic inclusions with a total mass of corundum of $763 \mathrm{~g}$ is calculated by the formula (Table 1):

$$
N_{N M I}^{p i}=763 / M_{N M I},
$$

where $M_{N M I}$ - mass of specific non-metallic inclusions, $\mathrm{g}$ (Table. 1):

$$
M_{N M I}=\frac{4}{3} \pi r^{3} \rho_{N M I}
$$

Table 1. The size of the primary inclusions of corundum depending on the time of their growth.

\begin{tabular}{|c|c|c|c|}
\hline $\begin{array}{c}\text { Growth time of } \\
\text { the primary } \\
\text { inclusions of } \\
\text { corundum, s }\end{array}$ & $\begin{array}{c}\text { The sizes of } \\
\text { inclusions of } \\
\text { corundum, } \\
\text { cm }\end{array}$ & $\begin{array}{c}\text { Mass of } \\
\text { corundum } \\
\text { inclusions, } \\
\text { g }\end{array}$ & $\begin{array}{c}\text { Number of } \\
\text { corundum } \\
\text { inclusions }\end{array}$ \\
\hline 0,0001 & 0,000363 & $2,46 \mathrm{e}^{-15}$ & $3,1 \mathrm{e}^{17}$ \\
\hline 0,0010 & 0,00147 & $4,44 \mathrm{e}^{-15}$ & $1,72 \mathrm{e}^{17}$ \\
\hline 0,0100 & 0,00363 & $9,53 \mathrm{e}^{-14}$ & $8,01 \mathrm{e}^{15}$ \\
\hline 0,1000 & 0,0115 & $3,87^{-11}$ & $1,97 \mathrm{e}^{13}$ \\
\hline
\end{tabular}

The rate of gravity sedimentation emergence of inclusions is determined by the formula:

$$
V_{g s}=2 g r\left(\rho_{m e l t}-\rho_{N M I}\right) / \eta,
$$

Where $g$ - acceleration of free fall, which is equal to 1000 $\mathrm{cm} / \mathrm{s}^{2} ; r$-radius of non-metallic inclusion, $\mathrm{cm} ; \rho_{\text {melt }}-$ melt density equal to $7.2 \mathrm{~g} / \mathrm{cm}^{3} ; \rho_{N M I}-$ density of non-metallic inclusion, which for oxidative non-metallic inclusion in the form of $\mathrm{Al}_{2} \mathrm{O}_{3}$ is equal to $4 \mathrm{~g} / \mathrm{cm}^{3} ; \eta$ - melt viscosity equal to $0.05 \mathrm{MPa} \cdot \mathrm{s}$.

The rate of ascent of the primary inclusions of corundum depending on the time of their growth is presented in Table 2.

Table 2. The rate of emergence of the primary inclusions of corundum depending on the time of their growth.

\begin{tabular}{|c|c|}
\hline $\begin{array}{c}\text { Growth time } \\
\text { the primary inclusions } \\
\text { of corundum, } \mathbf{p}\end{array}$ & $\begin{array}{c}\text { The rate of ascent of the } \\
\text { primary inclusions of } \\
\text { corundum, cm/s }\end{array}$ \\
\hline 0,0001 & 0,000363 \\
\hline 0,0010 & 0,00147 \\
\hline 0,0100 & 0,00363 \\
\hline 0,1000 & 0,0115 \\
\hline
\end{tabular}

For secondary inclusions, the equilibrium constant according to the Hoxen and Chipman formula [31] is similar to the equilibrium constant of the primary inclusions $K_{A l}^{s i}=10^{-12}$.

The initial oxygen content of $0.173 \%$ and the final oxygen content of $0.001 \%$ are taken. According to formula (8), the supersaturation of the melt is equal to:

$$
\alpha_{A l_{2} O_{3}}^{s i}=\frac{1,5^{2} \cdot 0,173^{3}}{10^{-12}}=3,89 e^{11} .
$$

According to formula (7), the critical radius of the embryo $\mathrm{Al}_{2} \mathrm{O}_{3}$ is equal to:

$$
r_{\mathrm{k}}^{\mathrm{si}}=\frac{2 \cdot 2337 \cdot 102}{4 \cdot 8,3143 \cdot 10^{7} \cdot 1973 \cdot \ln 3,89 e^{11}}=3,03 e^{-8} \mathrm{~cm} .
$$

For secondary inclusions according to formula (10), the growth of embryos is:

$$
r^{s i}=3,03 e^{-8}+2 \cdot 25,5 \cdot 1,5 \cdot 10^{-4}(0,173-0,001) t .
$$

We calculate the total mass of corundum, taking into account that $100000 \mathrm{~g}$ of melt contains $0.173 \cdot 100000 / 100$ $=173 \mathrm{~g}$ of oxygen $\left(\mathrm{O}_{2}\right)$. The mass of aluminum is: 173 . $54 / 48=194 \mathrm{~g}$. That is, the total mass of corundum is: 173 $+194=367 \mathrm{~g}$

The sizes of secondary inclusions depending on time of growth are presented in Table 3.

Table 3. The size of the secondary inclusions of corundum depending on the time of their growth.

\begin{tabular}{|c|c|c|c|}
\hline $\begin{array}{c}\text { Secondary } \\
\text { growth } \\
\text { time inclusions } \\
\text { corundum, } \\
\mathbf{s}\end{array}$ & $\begin{array}{c}\text { The size of } \\
\text { the } \\
\text { inclusions of } \\
\text { corundum, } \\
\text { cm }\end{array}$ & $\begin{array}{c}\text { Mass of } \\
\text { corundum } \\
\text { inclusions, } \\
\mathbf{g}\end{array}$ & $\begin{array}{c}\text { Number of } \\
\text { corundum } \\
\text { inclusions }\end{array}$ \\
\hline $1 \mathrm{e}^{-8}$ & $3,63 \mathrm{e}^{-6}$ & $7,8 \mathrm{e}^{-16}$ & $4,71 \mathrm{e}^{17}$ \\
\hline $1 \mathrm{e}^{-7}$ & $1,15 \mathrm{e}^{-5}$ & $2,53 \mathrm{e}^{-14}$ & $1,45 \mathrm{e}^{16}$ \\
\hline $1 \mathrm{e}^{-6}$ & $3,63 \mathrm{e}^{-5}$ & $7 \mathrm{e}^{-6} 8 \mathrm{e}^{-13}$ & $4,59 \mathrm{e}^{14}$ \\
\hline $1 \mathrm{e}^{-5}$ & $1,48 \mathrm{e}^{-4}$ & $2,53 \mathrm{e}^{-11}$ & $1,45 \mathrm{e}^{13}$ \\
\hline $1 \mathrm{e}^{-4}$ & $3,63 \mathrm{e}^{-4}$ & $7,99 \mathrm{e}^{-10}$ & $4,59 \mathrm{e}^{11}$ \\
\hline $1 \mathrm{e}^{-3}$ & $1,15 \mathrm{e}^{-3}$ & $2,53 \mathrm{e}^{-8}$ & $1,45 \mathrm{e}^{10}$ \\
\hline $1 \mathrm{e}^{-2}$ & $3,63 \mathrm{e}^{-3}$ & $7,99 \mathrm{e}^{-7}$ & 458915409 \\
\hline $1 \mathrm{e}^{-1}$ & 0,0115 & $2,53 \mathrm{e}^{-5}$ & 14512179 \\
\hline $1 \mathrm{e}^{0}$ & 0,036 & $7,99 \mathrm{e}^{-4}$ & 458915 \\
\hline $1 \mathrm{e}^{2}$ & 0,115 & 0,0253 & 14512 \\
\hline
\end{tabular}

The number of secondary non-metallic inclusions with a total mass of corundum of $367 \mathrm{~g}$ is calculated by the formula (Table 3):

$$
N_{N M I}^{s i}=367 / M_{N M I} .
$$

We assume the crystallization temperature of the formed layer of thermite alloy based on iron $1500{ }^{\circ} \mathrm{C}$, the average size of secondary oxide inclusions $1.03 \mathrm{e}^{-3} \mathrm{~cm}$, and the dynamic melt viscosity 4.26 MPa-s (Table 4).

According to formula (13) determine the rate of emergence of secondary inclusions.

Thus, in the melt with a thickness of $10 \mathrm{~cm}$, the rate of ascent of secondary inclusions is $1.59 \mathrm{e}^{-3} \mathrm{~cm} / \mathrm{s}$, and the time of ascent of secondary inclusions, respectively, $6289 \mathrm{~s}$. Therefore, the secondary inclusions are not removed from the thermite alloy and serve as centers for heterogeneous nucleation of chromium carbide 
inclusions.

Table. 4. Study of the viscosity of the steel grade ROM2SF10-MP [41].

\begin{tabular}{|c|c|c|c|}
\hline $\begin{array}{c}\text { Temperature, } \\
{ }^{\mathbf{0}} \mathbf{C}\end{array}$ & $\begin{array}{c}\text { Density, } \\
\mathbf{1 0}^{-3} \mathbf{~ k g} / \mathbf{m}^{3}\end{array}$ & $\begin{array}{c}\text { Dynamic } \\
\text { viscosity, } \\
\text { MPa·s }\end{array}$ & $\begin{array}{c}\text { Logarithm } \\
\text { of dynamic } \\
\text { viscosity }\end{array}$ \\
\hline 1400 & 6,60 & 11,70 & 2,460 \\
\hline 1440 & 6,50 & 7,87 & 2,063 \\
\hline 1450 & 6,40 & 7,23 & 1,978 \\
\hline 1460 & 6,30 & 4,66 & 1,540 \\
\hline 1500 & 6,12 & 4,26 & 1,451 \\
\hline 1510 & 6,07 & 3,97 & 1,382 \\
\hline 1520 & 6,02 & 2,93 & 1,041 \\
\hline 1530 & 5,97 & 2,82 & 1,038 \\
\hline 1550 & 5,88 & 2,77 & 1,020 \\
\hline
\end{tabular}

\section{Conclusions}

The calculation method of parameters formation of the primary and secondary nonmetallic inclusions in thermite alloys is offered. The regularities of the influence of the growth time of non-metallic inclusion in the form of corundum on its size, mass and quantity are analyzed. The regularities of the formation of chromium carbides around oxidative nonmetallic inclusions in the form of corundum during the crystallization of a thermite alloy are shown. The formation of chromium carbide inclusions occurs sequentially: first the homogeneous nucleation of corundum inclusions, and then the heterogeneous formation of chromium carbide inclusions. It is determined that the volume of the critical size of the nonmetallic inclusion in the form of $\mathrm{Al}_{2} \mathrm{O}_{3}$ is $3.85 \cdot 10^{-23}$ $\mathrm{cm}^{3}$, and in the form of $\mathrm{Cr}_{3} \mathrm{C}_{2}-2,746 \cdot 10^{-22} \mathrm{~cm}^{3}$.

It is shown that in a thermite alloy obtained by selfpropagating high-temperature synthesis, the average size of corundum inclusions surrounding the heterogeneous inclusions of chromium carbide is $15.4 \mu \mathrm{m}$. It is shown that in the process of alumothermic reactions of the SHS process a significant number of small inclusions of corundum is formed. This indicates that the alumina particles are dissolved in the alloy and they are the centers of crystallization and play the role of inoculating modifier. It is shown that secondary inclusions are not removed from the thermite alloy and serve as centers for heterogeneous nucleation of chromium carbide inclusions.

\section{References}

1. V.V. Lunev, The nature of non-metallic inclusions and the properties of the metal. Non-metallic inclusions and gases in foundry alloys: a collection of abstracts of the XIII International Scientific and Technical Conference (Zaporizhzhya, October 9-12, 2012). Zaporizhzhya: ZNTU. 7-8 (2012)

2. T.M. Titova, V.P. Poletaev, M.S. Beshkenadze, The role of non-metallic inclusions in steel. Non-metallic inclusions and gases in foundry alloys: a collection of abstracts of the XIII International Scientific and Technical Conference (Zaporizhzhya, October 9-12, 2012). Zaporizhzhya: ZNTU. 19-20 (2012)

3. S. Gubenko, Non-metallic inclusions and strength of steels. Physical bases of steel strength. Palmarium
Academic Publishing, 468 (2015)

4. K.V. Grigorovich, P.V. Krasovsky, A.S. Trushnikova, Analysis of non-metallic inclusions is the basis for quality control of steel and alloys. Analytics and control. 6(2), 133-142 (2002)

5. A.V. Kharchenko, R.V. Sinyakov, Physico-chemical regularities of formation of non-metallic inclusions in steel. Metallurgy. 1 (37), 17-23 (2017)

6. R. Kiessling, N. Lange, Non-metallic Inclusions in Steel. Parts I-IV. London: The Institute of Metals. (1978)

7. R. Kiessling, F.B. Pickering, Non-metallic Inclusions in Steel. Part V. London: The Institute of Metals (1989)

8. A.V. Kharchenko, R.V. Sinyakov. Thermodynamics of non-metallic inclusions in steel. Metallurgical and Mining Industry.3, 15-21 (2017)

9. L.S. Ozhigov, A.S. Mitrofanov, N.D. Ribalchenko, Y.A. Krainyuk, R.L. Vasilenko, S.V. Shramchenko, The effect of non-metallic inclusions in low-alloyed carbon steel on the service life of NPP pipe lines. Problems of atomic science and technology. 4(110), 59-64 (2017).

10. G.V. Serov, A.A. Komissarov, S.M. Tikhonov, E.P. Sidorova, I.V. Kushnerev, P.A. Mishnev, D.V. Kuznetsov, Deoxidizing effect on the low-alloyed steel's nonmetallic inclusion's compositions. New refractories. 12, 3-8 (2018). doi:10.17073/16834518-2018-12-3-8

11. A.B. Sychkov, M.A. Zhigarev, A.V. Perchatkin, V.I. Gritsayenko. Nonmetallic impurities in high carbon steel. Foundry production and metallurgy. 4, 74-82 (2012). doi:10.21122/1683-6065-2012-4-74-82

12. A.N. Romashkin, Development of a method for controlling the composition of non-metallic inclusions in steel for power engineering in order to minimize the negative impact of oxide particles on the properties of metal products: dis. ... Cand. tech. Science: 05.16.02. Moscow, 133 (2017)

13. T.V. Morozova, Influence of steel production technology on the homogeneity of the structure and contamination by non-metallic inclusions in order to increase the reliability of main pipelines: dis. ... Cand. tech. Science: 05.16.02. Moscow, 130 (2012)

14. A.A. Myasnikova, Non-metallic inclusions and their influence on the quality of welded joints in manual arc welding. Master. 50-54 (2012)

15. S.B. Gamanyuk, D.V. Rutskiy, N.A. Zyuban, M.V. Kirilichev, A research of impurity with nonmetallic inclusions in large ingots of $38 \mathrm{XN} 3 \mathrm{M} \Phi \mathrm{A}$ steel weighing 24.2 tons. University proceedings. Volga region. Engineering sciences. 1 (41), 115-127 (2017). doi:10.21685/2072-3059-2017-1-10

16. E.A. Krivonosova, T.V. Olshanskaya, T.V. Lodyagina, O.A. Burtseva, Influence of non-metallic inclusions and structural components on the toughness of low-alloy steel. Bulletin of the Perm National Research Polytechnic University. Mechanical engineering, materials science. 1, 94-100 (2014).

17. L.A. Smirnov, S.P. Burmasov, S.V. Belikov, A.Yu. 
Zhilyakov, A.S. Oryshchenko, G.Yu. Kalinin, I.V. Solovyov, M.E. Zhitlukhina, Effect of nonmetallic inclusions morphology on destruction of a perspective high strength corrosion-resistant steel 04Х20Н6Г11М2АФБ. Ferrous Metallurgy. Bulletin of Scientific, Technical and Economic Information. 76(4), 372-381 (2020). doi:10.32339/0135-59102020-4-372-381

18. S.A. Krylov, A.I. Shcherbakov, A.A. Makarov, O.A. Tonysheva, Reduction of non-metallic inclusions in the nitrogen-containing corrosion-resistant steels. Proceedings of VIAM. 5 (53), 3-13 (2017). doi:10.18577/2307-6046-2017-0-5-1-1

19. L.V. Kamkina, O.G. Bezshkurenko, Y.I. Sokur, A.A. Nadtochiy, V.S. Manidin, Influence of technological factors on the formation of non-metallic inclusions of carbon steel and technological recommendations for reducing their number. Modern problems of metallurgy. 17, 106-115 (2014)

20. S.I. Gubenko, V.V. Parusov, I.V. Derevyanchenko. Non-metallic inclusions in steel. Dnepropetrovsk: Art-press. 536 (2005)

21. A.A. Kazakov, A.I. Zhitenev, M.A. Salynova, Estimation of large single non-metallic inclusions in steel using statistics of extreme values. Ferrous metals. 11 (1043) (2018)

22. S.V. Terletski, V.V. Pivtsajev, A.V. Olenchenko, A.S. Zazjan, Technological peculiarities of melting and out-of-furnace processing of balanced steels in conditions of electric furnace steelmaking and continuous casting. Foundry production and metallurgy. 2, 29-33 (2007)

23. H.I. Spies, Behavior of nonmetallic inclusions in steel during crystallization and deformation. Moscow, Metallurgy, 125 (1971)

24. G.I. Belchenko, S.I. Gubenko, Non-metallic inclusions and steel quality. Kiev: Technology (1980)

25. Yu.P.Vorobyov, Carbides in steels. Proceedings of the Chelyabinsk Scientific Center. Issue. 2 (23), 3460 (2004)

26. O.A. Glotka, S.V. Haiduk, Distribution of elements in carbides of multicomponent superalloys.Metal physics and the latest technologies. 42(6), 869-884 (2020)

27. G. P. Dmitrieva, T. S. Cherepova, T. O. Kosorukova, V. I. Nichiporenko, Structure and properties of a wear-resistant alloy based on cobalt with niobium carbide. Metal physics and the latest technologies. 37 (7), 973-986 (2015)

28. B.S. Seplyarsky, R.A. Kochetkov, Investigation of $\mathrm{SH}$ synthesis of titanium carbide with nickel bond from powder and granular charge of bulk density. Nonisothermal phenomena and processes: from the theory of the thermal explosion to structural macrokinetics: materials of the III International Conference. To the 85th anniversary of the birth of Academician A.G. Merzhanov. Chernogolovka: ISMAN. 177-178 (2016)

29. A. I. Trotsan, V. V. Kaverinskiy, I. L. Brodetskiy,
Prediction of precipitation of carbonitrides and carbides in microalloyed steel, using thermodynamic calculations. Metal physics and the latest technologies. 35(7), 919-931. (2013)

30. A.A. Alekseenko, D.A. Ponomarenko, R.V. Sinyakov, Calculation of chemical composition and total mass of non-metallic inclusions in the course of out-of-furnace processing and casting of steel. Part 1 . Models. Modern problems of metallurgy have become: materials of the XV International scientific conference. Chelyabinsk.(IOP Publishing PhysicsWeb, 2014), http://www.steelmaker.ru/ru/node/2515. Accessed 26 November 2020

31. A.T. Yevtushenko, Self-propagating hightemperature synthesis of tool steel. Bulletin of the Tomsk Polytechnic University. 313(3),100-104 (2008)

32. I.E. Skidin, V.T. Kalinin, V.V. Tkach, L.N. Saitkhareiev, O.M. Zhbanova, Alternative technology to manufacture bimetallic products by using self-propagating high temperature synthesis. Journal of Engineering Sciences 4 (2), B7-B10 (2017). doi:10.21272 / jes.2017.4 (2).b7

33. I.E. Skidin, B.F. Belov, O.S. Vodennikova, S.A. Vodennikov, Structural and chemical state of surfacing of a thermite alloy on a steel substrate by the aluminothermic SHS process. Proceedings of the VI International Scientific and Practical Conference «Modern Technologies of the Industrial Complex 2020» (Kherson, September 8-12, 2020). Kherson: KhNTU. 6, 144-148 (2020)

34. G. Knuppel, Deoxidation and vacuum treatment of steel. Part 1 Thermodynamic and kinetic regularities. Per. with him. G.N. Elanskiy. Moscow: Metallurgy. 312 (1973)

35. V.A. Mchedlishvili, Thermodynamics and kinetics of steel deoxidation. Moscow, Metallurgy, 288 (1967)

36. O. A. Bannykh, P. B. Budberg, S. P. Alisova et al. Phase Diagrams of Binary and Multicomponent Iron Systems. Mosvka: Metallurgy. 440 (1986)

37. V.I. Yavoisky, Theory of steel production processes. Moscow, Metallurgy. 792 (1967)

38. L. Bogdandy, Arch. Eisenhüttenwesen. 32, 275/96 (1961)

39. I.N. Beckman, Higher mathematics: the mathematical apparatus of diffusion: a textbook for bachelor's and master's degrees. 2nd ed., Corrected. and ext. Moscow, Yurayt Publishing House. 459 (2017)

40. T.I. Trofimova, Physics course: textbook. manual for universities. 11th ed., Mosvka: Academy. 560 (2006)

41. S.L. Makurov, Fusion and viscosity of molten highvanadium steels investigation with the aim of perfecting the powder obtaining from liquid state by sputtering.Reporter of the Priazovskyi State Technical University. Series: technical sciences. 36, 22-28 (2018). doi: 10.31498/22256733.36.2018.142511 